\title{
APLIKASI BERBASIS ANDROID SEBAGAI LAYANAN PEMESANAN AMBULANS STUDI KASUS PUSKESMAS AIK DAREK
}

\author{
Nasrullah', Muhammad Fauzi Zulkarnaen², Maemun Saleh ${ }^{3}$ \\ STMIK LombokPraya, Indonesia \\ Program StudiTeknik Informatika

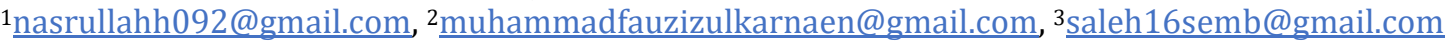

\begin{abstract}
Ambulance is a transportation unit provided by the Public Health Center (PUSKESMAS). One of them is PUSKESMAS Aik Darek which provides ambulance services that are used to help the societyin providing first aid and intensive care when patients are on their way to the referral hospital. In ordering an ambulance by the society, the PUSKESMAS often had difficulty finding the location of the society who ordered the ambulance.

To resolvethe problems that are currently occurring at the Aik Darek PUSKESMAS, the system analysis process uses the SWOT (Strength, Weakness, Opprtunity, Threats)method. The system design in this study uses traditional development methods, namely SDLC (System Development Life Cycle). In the development of applications utilizing technology provided by Google, namely Google Maps Api, Database using Firebase, and tools used in making applications using Android Studio.

The result of this research is to produce an Android-based application that will help the society in an ambulance order. The society will order an ambulance by sending incident data in the form of incident images, information, and the location of the incident, so that the PUSKESMAS will be able to find out the location of the society who ordered the ambulance. The society will also be able to monitor the current location of the PUSKESMAS.
\end{abstract}

Keywords : ambulance, android studio, google maps api, SDLC, SWOT

\begin{abstract}
Abstrak
Ambulans adalah sebuah unit transportasi yang disediakan oleh pihak Pusat Kesehatan Masyarakat ( PUSKESMAS ). Salah satunya adalah PUSKESMAS Aik Darek yang menyediakan layanan ambulans yang diguakan untuk membatu masyarakat dalam memberikan pertolongan pertama dan perawatan intensif saat pasien berada dalam perjalanan menuju rumah sakit rujukan.

Dalam pemesanan ambulans oleh masyarakat, pihak PUSKESMAS sering kali mengalami kesulitan dalam menemukan lokasi masyarakat yang memesan ambulans.

Untuk mengatasi permasalahan yang sedang terjadi pada PUSKESMAS Aik Darek, proses analisa sistem menggunakan metode SWOTStrength (kekuatan), Weakness (kelemahan), Opprtunity (peluang), Threats (ancaman).Perancangan sistem pada penelitian ini menggunakan metode pengembangan tradisional yaitu SDLC (System Development Life Cycle). Dalam pengembangan aplikasi memanfaatkan teknologi yang disediakan oleh Google yaitu Google Maps Api,Database meggunakan Firebase, dan tools yang digunakan dalam pembuatan aplikasi menggunakan Android Studio.

Hasil dari penelitian ini adalah menghasilkan aplikasi berbasis android yang akan membantu masyarakat dalam mesanan ambulans. Masyarakat nantinya akan memesan ambulans dengan mengirim data kejadian berupa gambar kejadian, keterangan, dan titik lokasi kejadian, sehingga pihak PSKESMAS nantinya bisa mengetahui rute lokasi masyarakat yang memesan ambulans. Masyarakat nantinya juga bisa memantau lokasi terkini dari pihak PUSKESMAS.
\end{abstract}

Kata kunci : ambulans, android studio,google maps api, SDLC, SWOT 


\section{Pendahuluan}

Kecamatan Batukliang terletak di bagian Utara dari Kabupaten Lombok Tengah dengan luas wilayah sekitar 5.037 ha dengan jumlah penduduk 76.332 jiwa. Secara geografis Kecamatan Batukliang memiliki batas-batas wilayah yaitu sebelah Utara Kecamatan Batukliang Utara, sebelah Timur Kecamatan Kopang, sebelah Selatan Kecamatan Praya, sebelah Barat Kecamatan Pringgarata.

Pusat Kesehatan Masyarakat (PUSKESMAS) adalah sebuah unit tempat pelayanan masyarakat dalam dalam bidang kesehatan. Keberadaan PUSKESMAS di lingkungan masyarakat sangat membantu masyarakat dalam mengatasidalam bidang kesehatan dikarenakan layanan PUSKESMAS mudah di jangkauoleh masyarakat setempat.

Dalam pemesanan ambulans masyarakat akan menghubungi nomor telepon sopir ambulans yang telah di sediakan oleh pihak PUSKESMAS. Masyarakat yang akan menggunakan layanan ambulans harus memberikan alamat yang lengkap sehingga sopir ambulans tersebut bisa mengetahui lokasi masyarakat yang membutuhkan layana ambulans tersebut. Sopir ambulans sering mengalami kesulitan dalam menangani masyarakat ketika lokasi yang akan di tuju adalah lokasi yang tepelosok atau jarang di lalui oleh sopir tersebut.

\section{Tinjuan Pustaka}

Nina Sevani dan Tadhan Emmanuel (2013) dalam penelitiannya Sistem Permintaan Layanan Ambulans Dengan SMS Gateway Pada Rumah Sakit [1]. Sistem ini dibangun dengan aplikasi yang memanfaatkan SMS Gateway dengan berbasiskan web sebagai Interface bagi administrator di rumah sakit. Aplikasi ini bertujuan untuk membantu pihak rumah sakit dalam memantau pesan permintaan ambulans yang masuk. Sebuah aplikasi berbasis android juga dibuat untuk dapat menunjang kemudahan pasien dalam mengirimkan pesan singkat.

Bayu Astaka dkk (2017) dalam penelitiannya Aplikasi Bantuan Darurat Untuk Android Dengan Perintah Suara. Aplikasi ini dibangun megguakan bahasa pemrograman PHP dan database MYSQL [2]. Tahap pegembangan aplikasi meliputi analisis, perancangan sistem, implementasi dan pengujian. Tujuan dari pembangunan aplikasi adalah untuk mempermudah dalam mencari bantuan darurat yang dibutuhkan untuk menangani suatu keadaan darurat. Sehingga dapat memberikan kemudahan kepada masyarakat dalam mecari informasi layanan publik terdekat seperti polisi, rumah sakit ambulans dan bengkel sebagai bantuan darurat.

Vonny Anggraeni Purnomo dan Wijanarto (2013) dalam penelitiannya Rancang Bangun Aplikasi Penyedia Layanan Ambulans Meggunakan Teknologi GIS, GSM dan GPS (GPRS) [3]. Penelitian ini dilakukan untuk membagun aplikasi pengadaan ambulans dengan sistem informasi geografis berbasis web (onlnie) dengan memanfaatkan HP android GPS untuk mengetahui latitude dan longitude dari suatu lokasi. Dengan memanfaatkan GoogleMasp Api posisi mobil ambulans akan di visualkan dalam bentuk peta digital untuk dapat melakukan pelacakan mobil ambulans yang tersedia.

Marda Nova (2018) dalam penelitiannya Aplikasi Layanan Ambulans Untuk Situasi Darurat Berbasis Android. Aplikasi ini dibangun menggunakan adroid studio, dan menggunakan DFD dalam perancangan, dengan memanfaatkan tekonologi Location Based Service (LBS) yang merupakan layanan informasi yang memafaatkan untuk menunjukkan lokasi atau GPS (Global Position System) yang dapat mencari letak sebuah tempat atau lokasi [4]. Hasil dari penelitiannya adalah aplikasi layanan ambulans untuk situasi darurat berbasis android, pengguna dapat mengakses aplikasi untuk mengirim pesan darurat ke rumah sakit terdkat yang sudah terdaftar, melihat daftar ambulans, yang sudah terdaftar di aplikasi dan mengetahui dimana posisi kita saat ini. Sedangkan admin webserver dapat menghapus dan mengolah pesanan dari pelanggan melalui website.

Masdui Kartasasmita dkk (2017) dalam penelitiannya Penentuan Jarak Efisien Pengantaran Pasien Oleh Ambulans Ke RSUD Karawang Dengan AlgoritmaJikstra. Metode penelitian yang digunakan dalam membangun sistem adalah metode SDLC Waterfall yaitu suatu metodologi pengembangan perangkat lunak yang mengusulkan pendekatan kepada perangkat lunak sistematik dan sekuensial [5]. Dalam penelitiannya bertujuan untuk memberikan solusi kepada pihak ambulans untuk menentukan rute dalam pengantaran pasien ke RSUD karawang dengan menggunakan algoritma jikstra, sehingga dapat diimplementasikan 
sebagai alteratif dalam penentuan jarak efisiensi dalam pengantaran pasien oleh ambulans ke RSUD Karawang.

\section{Metodologi Penelitian}

1. Metode Pengumpulan data

a. Observasi

Melakukan penelitian secara langsung ke UPT BLUD PUSKESMAS Aik Darek untuk memperoleh data-data yang dibutuhkkan dalam perancangan.

b. Wawancara

Mengajukan pertanyaan secara langsung kepada kepala UPT BLUD PUSKESMAS Aik Darek.

c. Srudi Literatur Pustaka

Metode pengumpulan data dengan menggunakan refrensi dari jurnal karya ilmiah atau menggunakan refrensi dari sumber internet.

2. Metode Analisa

Dalam penelitian ini metode analisa yang digunakan yaitu metodeAnalisis SWOT untuk mendapatkan informasi dari analisis situasi dan memisahkannya dalam pokok persoalan internal Strength (kekuatan) danWeakness(kelemahan) dan pokok persoalan eksternal Opportunity(peluang) danThreats (ancaman).

3. Metode Perancangan

Perancangan Sistem pada penelitian ini menggunakan metode pengembangan tradisional yaitu SDLC( SystemDevelopment Life Cycle ). Pengembangan sistem menggunakan metode SDLC ini terdiri dari beberapa fase yakni mulai dari tahap Perencanaan (planning), Analisis (analysis), Desain ( design ), Implementasi ( implementation ), Uji Coba ( testing )dan Perawatan(maintenance).

\section{Hasil dan Pembahasan}

4.1 Perancangan Proses

1 Usecase Diagram

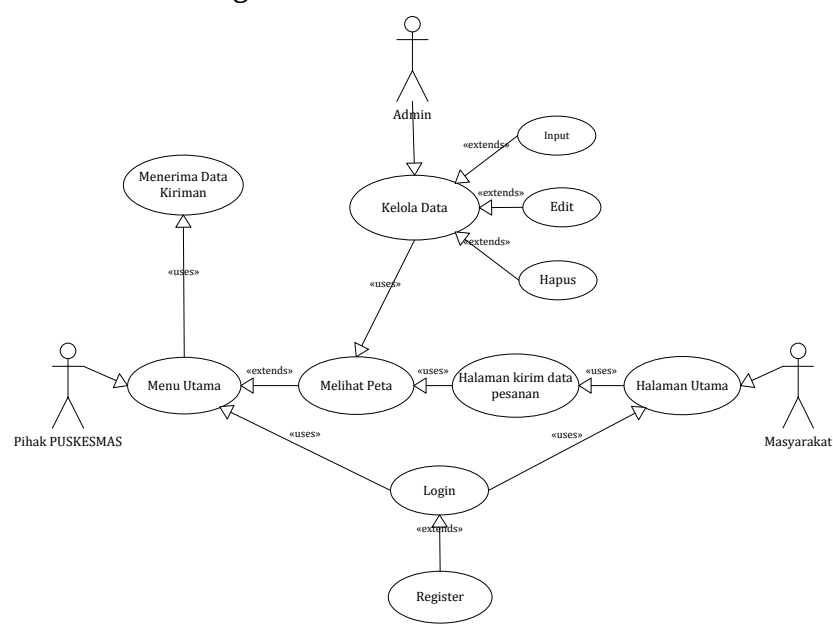

Gambar 4.1 UseCase Diagram

Gambar 3.2 menjelaskan sistem Use Case Diagram menampilkan aktor yang menggunakan sistem yaitu admin, Pihak PUSKESMAS, dan masyarakat. Admin yang bertugas sebagai menginput, menghapus dan mengedit data yang dibutuhkan dalam menjalani aplikasi.

\subsection{Activity Diagram}

1 Proses Login

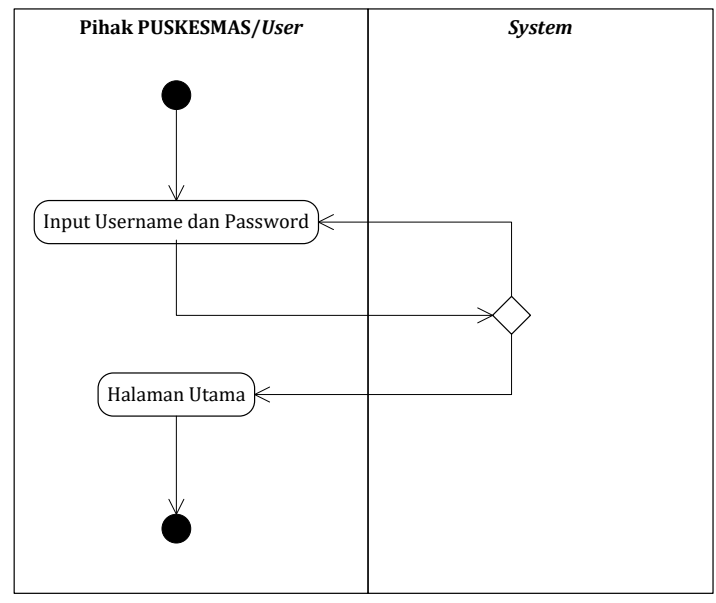

Gambar 4.2 Proses Login 
Gambar 4.2 menjelaskan bagaimana proses login yang dilakukan User menginputkan username dan password ke dalam sistem.

\section{Proses RegistrasiUser}

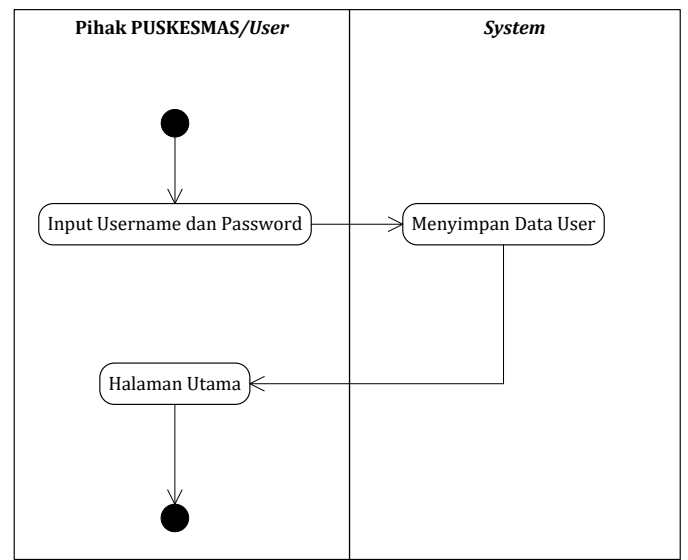

Gambar 4.3Proses Registrasi User

Gambar 4.3 menjelaskan bagaimana proses registrasi yang dilakukan oleh usermenginputkan email dan password kedalam text inputan. Kemudian sistem akan mengolah hasil inputan dan melakukan penyimpanan data kedalam database.

3 Proses Pemesanan Ambulans

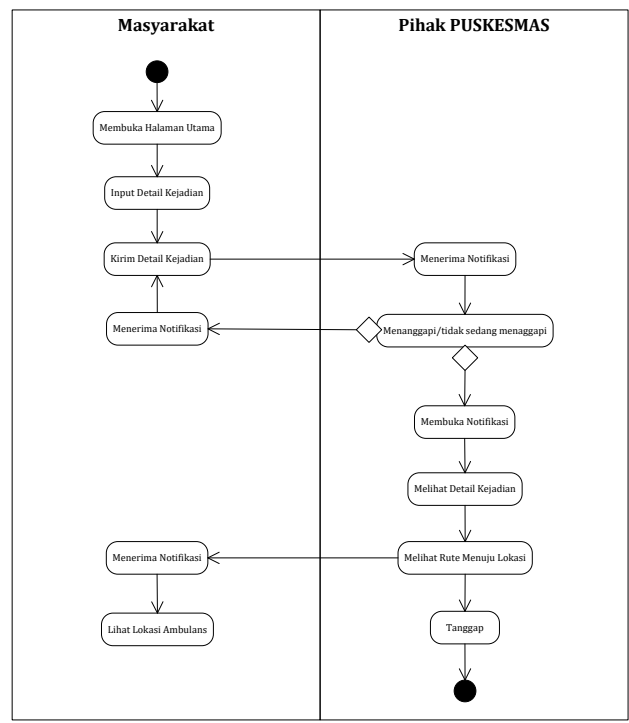

Gambar 4.4 Prses Pemesanan Ambulans

Gambar 4.4 menjelaskan bagaimana proses pemesanan ambulanns oleh Masyarakat ke pihak PUSKESMAS.
4 ProsesPengolahan Data oleh Admin

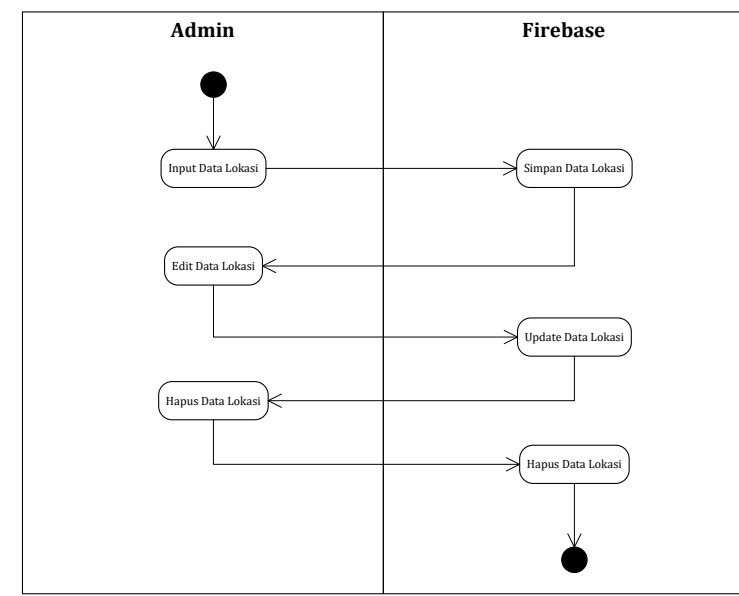

Gambar 4.5 Pengolahan Data oleh Admin

Gambar 4.5 menjelaskan bagaimana proses pengolahan data oleh admin. Admin melakukan proses penginputan data ke dalam sistem yang selanjutnya disimpan di database firbase. Selanjutnya admin juga dapat melakukan proses update maupun delete data yang sebelumnya sudah di inputkan.

\section{Proses Logout}

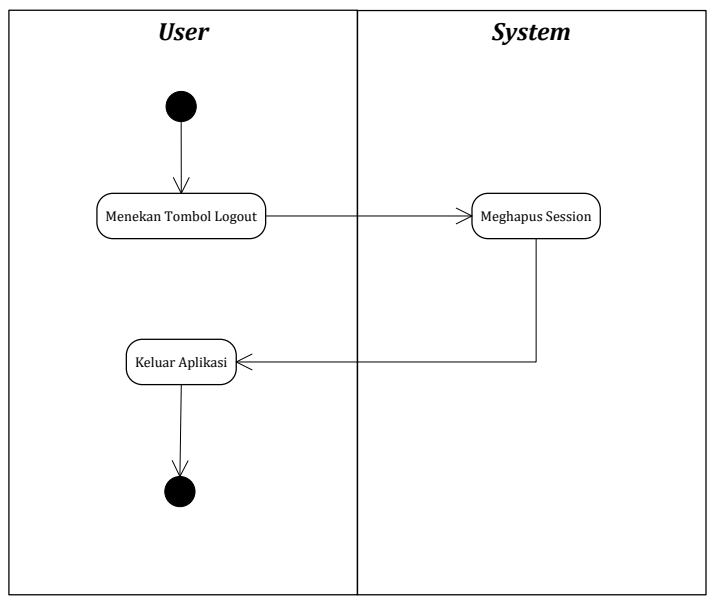

Gambar 4.6 Proses Logout

Gambar 4.6 menjelaskan bagaimana proses logout atau keluar dari aplikasi yakni, oleh user menekan tombol logout dan kemudian oleh sistem menghapus session dari user tersebut. Setelah itu, oleh sistem mengalihkan user ke halaman login. 


\subsection{Class Diagram}

\begin{tabular}{|c|c|c|c|c|}
\hline petugas & \multirow{4}{*}{$\frac{\text { Eirepd }}{1 *}$} & pesan & \multirow[b]{2}{*}{$\begin{array}{c}-\underbrace{-E n d 3}_{* n} \\
\text {-End4 }\end{array}$} & user \\
\hline $\begin{array}{l}\text {-id_petugass : Char = * } \\
\text {-email : Char } \\
\text {-password : Char } \\
\text {-no_hp : Integer } \\
\text {-foto : Char } \\
\text {-lat : Double } \\
\text {-long : Double }\end{array}$ & & \multirow[t]{2}{*}{$\begin{array}{l}\text {-id_pesan : Char }={ }^{*} \\
\text {-id_petugas : Char }={ }^{*} \\
\text {-id_user : Char }={ }^{* *} \\
\text {-foto: Char } \\
\text {-no_hp: Integer } \\
\text {-keterangan : Char } \\
\text {-lat : Double } \\
\text {-long : Double }\end{array}$} & & $\begin{array}{l}\text {-id_user : Char = * } \\
\text {-email : Char } \\
\text {-password : Char } \\
\text {-no_hp : Integer } \\
\text {-foto : Char } \\
\text {-lat : Double } \\
\text {-long : Double }\end{array}$ \\
\hline$++\operatorname{tambah}()$ & & & & $+\operatorname{tambah}()$ \\
\hline $\begin{array}{l}\text { +hapus() } \\
\text { +edit() }\end{array}$ & & $\begin{array}{l}+ \text { tambah() } \\
+ \text { hapus() }\end{array}$ & & $\begin{array}{l}\text { +hapus() } \\
\text { +edit() }\end{array}$ \\
\hline
\end{tabular}

Gambar 4.6 Class Diagram

Gambar 4.6 menjelaskan class diagram merupakan gambaran struktur data yang menjadi dasar dari pembangunan Aplikasi Pemesanan Ambulans Studi Kasus PUSKESMAS Aik Darek.

\subsection{Interace}

Interface adalah salah satu layanan yang disediakan oleh sistem operasi sebagai sarana interaksi antara pengguna dengan sistem informasi. Berikut beberapa interface yang dirancang oleh penulis dan fungsi dari interface tersebut.

Halaman login merupakan halaman yang akan ditampilkan oleh aplikasi ketika user atau pengguna menginstal atau membuka aplikasi untuk pertama kali. Halaman login digunakan sebagai proses authentification atau proses pengecekan akun sebagai syarat untuk dapat masuk ke halaman utama aplikasi.

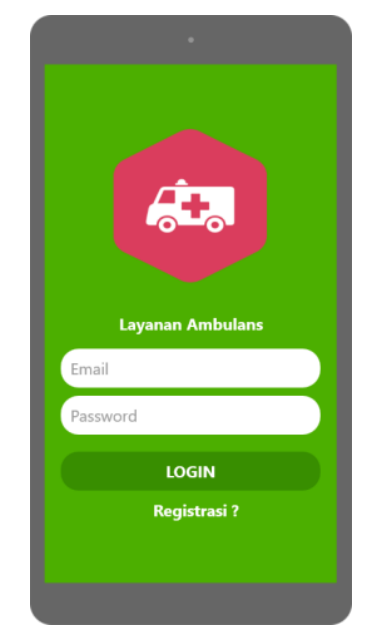

Gambar 4.7 Halaman Login
Halaman registrasi digunakan untuk melakukan pendaftaran akun baru oleh user atau pengguna. Proses registrasi dilakukan dengan cara memasukan username, email, no handphone dan password.

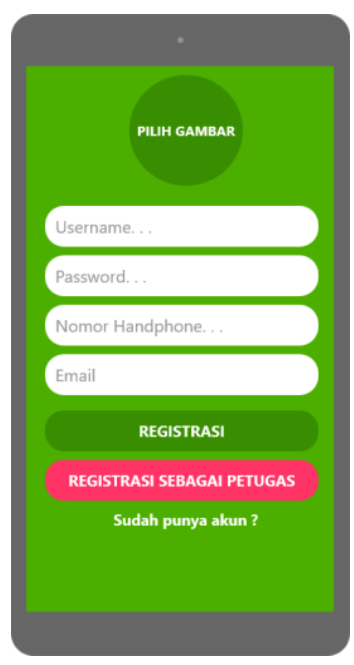

Gamabar 4.8 Halaman Registrasi

Halaman Input Pesan digunakan untuk melakukan penginputan terhadap data yang akan dikirim ke petugas seperti gambar kejadian, keterangan, no handphoe, latitude dan longitde.

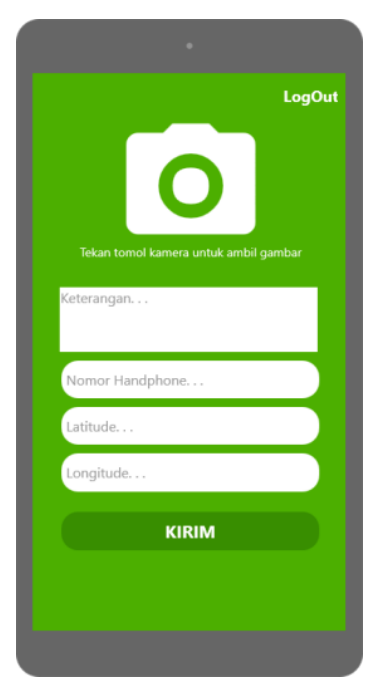

Gambar 4.9 Halaman Input Pesan

Halaman Detail Pesan merupakan halaman yang akan manampilkan detail data yang dikirim oleh pengguna berupa gambar, keterangan, no hadphone dan titik lokasi atau latitude dan longitude. 


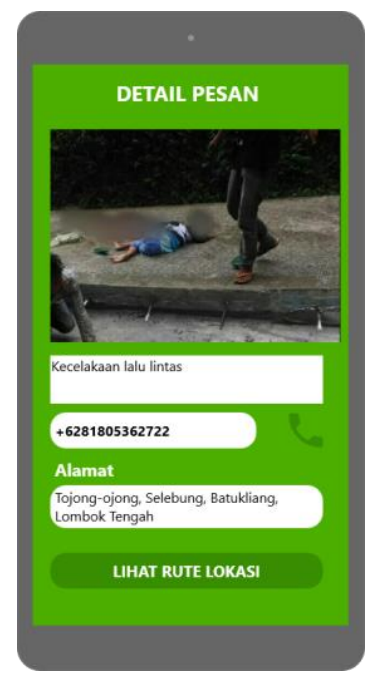

Gambar 4.10 Halaman Detail Pesan

Halaman Riwayat Pesan merupakan halaman yang akan menampilkan riwayat pesan yang dikirim oleh pengguna.

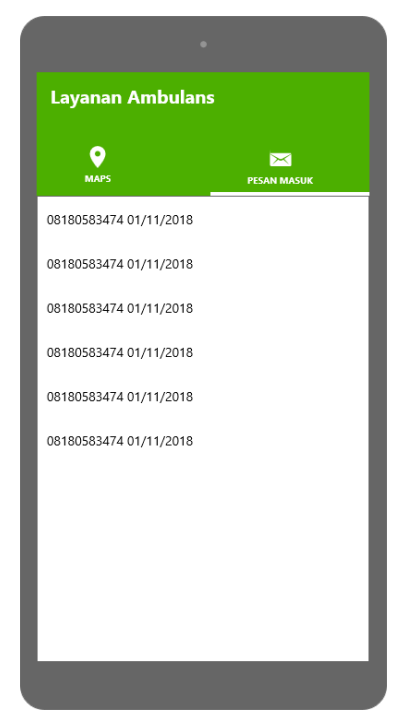

Gambar 4.11 Halaman Riwayat Pesan

Halaman Rute Lokasi merupakan halaman yang akan menampilkan rute lokasi berdasarkan titik lokasi (latitude dan longitude)yang dikirim oleh pengguna.

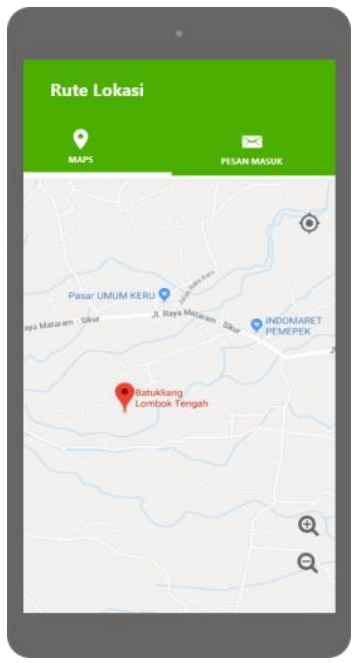

Gambar 4.12 Halaman Rute Lokasi Halaman Admin merupakan halaman yang akan menampilkan proses admin melakukan pengelolaan data yang ada pada tabel user dan pesan.

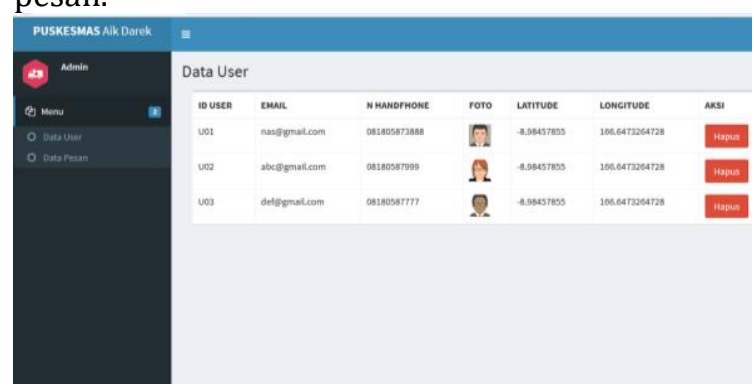

\section{Kesimpulan dan saran}

Gambar 4.13 Halaman Admin

\subsection{Kesimpulan}

Dari penelitian perancangan aplikasi yang diusulkan dapat disimpulkan bahwa aplikasi berbasis android yang dikembangkan mampu membantu masyarakat dalam memesan ambulans di PUSKESMAS Aik Darek.

\subsection{Saran}

Berdasarkan hasil penelitian yang dilakukan, maka saran yang perlu di perhatikan dalam proses pengembangan aplikasi ini adalah sebagai berikut :

1. Apllikasi dapat dikembangkan untuk jangkauan yang lebih luas agar pengguna dapat memesan layanan ambulans ke PESKESMAS terdekat berdasarkan lokasi saat ini. 
2. Aplikasi dapat kompetibel dengan versi android di bawah 5.0 (Lolipop).

3. Aplikasi mampu menghasilkan laporan untuk petugas.

\section{Daftar Pustaka:}

Sevani N. dan Emmanel T. 2013. Sistem Permintaan Layanan AmbulansDengan SMS Gateway Pada Rumah Sakit. Vol 02 No. 07 ,Juli-September 2013

Astaka B. dkk. 2017. Aplikasi Bantuan Darurat Untuk Android Dengan Perintah Suara. Program Studi Teknik Informatika Fakultas Teknik Universitas PGRI Yogyakarta 2017

Purnomo V. A. Dan wijanarto. 2013. Rancang Bangun Aplikasi PenyediaLayanan Ambulans Meggunakan Teknologi GIS, GSM dan GPS (GPRS). Techno.COM, Vol. 12, No. 3, Agustus 2013: 150-156

Nova M. 2018. Aplikasi Layanan Ambulans Untuk Situasi Darurat Berbasis Android.Jurusan Teknik Informatika Fakultas Teknologi Industri Universitas Islam Indonesia 2018

Haris, N., Imtihan, K., \& Ashari, M. (2018). PERANCANGAN SISTEM INFORMASI PENGOLAHAN DATA NILAI SISWA BERBASIS WEB DI SMKN 1 PRAYA. Jurnal Manajemen Informatika dan Sistem Informasi, 1(2), 55-61.

Rohana, R., \& Imtihan, K. (2018). Sistem Informasi Keluhan Pelanggan Pada Perusahaan Daerah Air Minum (PDAM) Kabupaten Lombok Tengah.Jurnal Manajemen Informatika dan Sistem Informasi, 1(1), 24-30.

Fadli, S., \& Imtihan, K. (2018). ANALISIS DAN PERANCANGAN SISTEM ADMINISTRASI DAN TRANSAKSI BERBASIS CLIENT SERVER. Jurnal Informatika dan Rekayasa Elektronik, 1(2), 7-14.
Kartasasmita M. Dkk. 2017. Penentuan Jarak Efisien Pengantaran Pasien OlehAmbulans Ke RSUD Karawang Dengan AlgoritmaJikstra. ILKOM Jurnal Ilmiah Volume 9 Nomor 3 Desember 2017

Dharwiyanti S dan Wahyono R. S, Pengantar Unified Modeling Language (UML). Kuliah Umum Ilmu Komputer.com 2013

Mahdia F. dan Nofiyato F. 2013. Pemanfaatan Google Maps Api UntukPembangunan Sistem Informasi Manajemen Bantuan Logistik Pasca Bencana Alam Berbasis Mobile Web. Volume 1 Nomor 1, Juni 2013

Rismayani. 2016. Pemanfaatan Teknologi Google Maps API Untuk AplikasiLaporan Kriminal Berbasis Android Pada Polrestabes Makassar. Jurnal Penelitian Pos dan Informatika Vol. 6, No 2 , (2016) 185 200

Pitriyawati, M., \& Imtihan, K. (2018). Sistem Informasi Kenaikan Pangkat Karyawan Pada Dinas Pekerjaan Umum (PU) Dan Energi Sumber Daya Mineral (ESDM) Kabupaten Lombok Tengah. Jurnal Manajemen Informatika dan Sistem Informasi, 1(1), 31-38.

Lukman, M., Bagye, W., Fahmi, H., \& Imtihan, K. (2019). PEMANFAATAN TEKNOLOGI GOOGLE MAPS API UNTUK APLIKASI PENDETAKSIAN LOKASI RAWAN KRIMINALITAS BERBASIS ANDROID Studi kasus: Desa Ganti dan Desa Mujur, Kecamatan Praya Timur, Kabupaten Lombok Tengah. Jurnal Informatika dan Rekayasa Elektronik, 2(1), 52-59. 